\title{
DRIVER ASSESSMENT AND TRAINING IN THE 1980s AND THE 1990s: AN ANALYSIS OF THE MOST-CITED PUBLICATIONS
}

\author{
Michael Sivak \\ Michael J. Flannagan \\ Brandon Schoettle \\ The University of Michigan \\ Transportation Research Institute \\ Ann Arbor, MI 48109-2150 \\ E-mail:sivak@umich.edu
}

\begin{abstract}
Summary: This study analyzed the most-cited publications in the area of driver assessment and training. The citation counts were obtained from both the Science Citation and Social Science Citation databases, which at the time of the analysis contained a total of over 27 million items. The search was restricted to items that were published during the 20-year period from 1980 through 1999 . The focus of the search was on the assessment and training of driving-related skills. In addition to documenting the most influential publications, the results are also presented in terms of changes over time by topic and by publication outlets.
\end{abstract}

\section{INTRODUCTION}

The purpose of this study was to provide an indication of the most-cited publications in the area of driver assessment and training. To do that, we searched two Web-of-Science databases developed by the Institute for Scientific Research for literature published during the 1980s and 1990s.

\section{METHOD}

The databases searched were the Science Citation Index Expanded and the Social Sciences Citation Index. The topics of interest were assessment and training of driving-related skills. The specific search terms were as follows:

(driver OR drivers OR driving OR car OR cars) AND (evaluation OR assessment OR performance OR ability OR abilities OR training OR vision OR visual OR perception OR perceptual OR cognition OR cognitive OR attention OR attentional OR information processing OR sensory OR psychomotor)

Citation frequencies were obtained for publications that met the above topical constraint and were dated 1980 through 1999. (The date restriction was on the cited publications, not on the citing publications.) At the time of the computerized search (in May 2001) the two searched databases contained 16.9 million documents dated 1980 through 1999 (out of a total of 27.4 million documents).

\section{RESULTS}

The most-cited publications are shown in Tables 1 through 4, classified by four five-year periods of publication date (1980-1984, 1985-1989, 1990-1994, and 1995-1999). Each table shows the 10 most-cited publications, except that 11 publications are shown for the 1995-1999 time period because of ties. 
Table 1

The most-cited publications: 1980-1984. (The numbers on the left indicate the number of the citations.)

117 Moskowitz, H., and Smiley, A. (1982). Effects of chronically administered Buspirone and Diazepam on driving-related skills performance. Journal of Clinical Psychiatry, 43, 45-55.

109 Hindmarch, I., and Gudgeon, A.C. (1980). The effects of Clobazam and Lorazepam on aspects of psychomotor performance and car handling ability. British Journal of Clinical Pharmacology, 10, 145-150.

95 Johnson, C.A., and Keltner, J.L. (1983). Incidence of visual-field loss in 20,000 eyes and it's relationship to driving performance. Archives of Ophthalmology, 101, 371-375.

66 Sivak, M., Olson, P., Kewman, D.G., et al. (1981). Driving and perceptual-cognitive skills: Behavioral consequences of brain damage. Archives of Physical Medicine and Rehabilitation, 62, 476-483.

60 Hills, B.L. (1980). Vision, visibility and perception in driving. Perception, 9, 183-216.

54 Betts, T., Markman, D., and Debenham, S., et al. (1984). Effects of 2 antihistamine drugs on actual driving performance. British Medical Journal, 288, 281-282.

48 Hindmarch, I., Subhan, Z., and Stoker, M.J. (1983). The effects of Zimeldine and Amitriptyline on car driving and psychomotor performance. Acta Psychiatrica Scandinavica, 68 (Suppl. 308), 141-146.

42 deGier, J.J., 't Hart, B.J., Nelemans, F.A., et al. (1981). Psychomotor performance and real driving performance of outpatients receiving diazepam. Psychopharmacology, 73, 340-344.

39 Sivak, M., Hill, C.S., Henson, D.L., et al. (1984). Improved driving performance following perceptual training in persons with brain damage. Archives of Physical Medicine and Rehabilitation, 65, 163167.

27 Betts, T.A., and Birtle, J. (1982). Effect of 2 hypnotic drugs on actual driving performance next morning. British Medical Journal, 285, 852-852.

Table 2

The most-cited publications: 1985-1989. (The numbers on the left indicate the number of the citations.)

84 Findley, L.J., Fabrizio, M.J., Knight, H., et al. (1989). Driving simulator performance in patients with sleep-apnea. American Review of Respiratory Disease, 140, 529-530.

63 Finn, P., and Bragg, B.W.E. (1986). Perception of the risk of an accident by young and older drivers. Accident Analysis and Prevention, 18, 289-298.

53 Matthews, M.L., and Moran, A.R. (1986). Age-differences in male drivers' perception of accident risk: The role of perceived driving ability. Accident Analysis and Prevention, 18, 299-313.

47 Saltz, R.F. (1987). The roles of bars and restaurants in preventing alcohol-impaired driving: An evaluation of server intervention. Evaluation \& the Health Professions, 10, 5-27.

39 Russ, N.W., and Geller, E.S. (1987). Training bar personnel to prevent drunken driving: A fieldevaluation. American Journal of Public Health, 77, 952-954.

37 Groeger, J.A. and Brown, I.D. (1989). Assessing ones own and others driving ability: Influences of sex, age, and experience. Accident Analysis and Prevention, 21, 155-168.

36 Retchin, S.M., Cox, J., Fox, M., et al. (1988). Performance-based measurements among elderly drivers and nondrivers. Journal of the American Geriatrics Society, 36, 813-819.

32 Keltner, J.L., and Johnson, C.A. (1987). Visual function, driving safety, and the elderly. Ophthalmology, 94, 1180-1188.

31 Stokx, L.C., and Gaillard, A.W.K. (1986). Task and driving performance of patients with a severe concussion of the brain. Journal of Clinical and Experimental Neuropsychology, 8, 421-530.

26 McCormick, I.A., Walkey, F.H., and Green, D.E. (1986). Comparative perceptions of driving ability A confirmation and expansion. Accident Analysis and Prevention, 18, 205-208. 
Table 3

The most-cited publications: 1990-1994. (The numbers on the left indicate the number of the citations.)

133 Engleman, H.M., Martin, S.E., Deary, I.J., et al. (1994). Effect of continuous positive airway pressure treatment on daytime function in sleep apnea/hypopoea syndrome. Lancet, 343, 572-575.

113 Ray, W.A., Fought R.L., and Decker, M.D. (1992). Psychoactive-drugs and the risk of injurious motor-vehicle crashes in elderly drivers. American Journal of Epidemiology, 136, 873-883.

111 Mangione, C.M., Phillips, R.S., Seddon, J.M., et al. (1992). Development of the activities of daily vision scale - A measure of visual function status. Medical Care, 30, 1111-1126.

84 Quadrel, M.J., Fischhoff, B., and Davis, W. (1993). Adolescent (in)vulnerability. American Psychologist, 48, 102-116.

79 Owsley, C., Sloane, M.E., Ball, K., et al. (1991). Visual cognitive correlates of vehicle accidents in older drivers. Psychology and Aging, 6, 403-415.

72 Brenner, M.H., Curbow, B., Javitt, J.C., et al. (1993). Vision change and quality-of-life in the elderly - Response to cataract-surgery and treatment of other chronic ocular conditions. Archives of Ophthalmology, 111, 680-685.

69 Ball, K., Owsley, C., Sloane, M.E., et al. (1993). Visual-attention problems as a predictor of vehicle crashes in older drivers. Investigative Ophthalmology \& Visual Science, 34, 3110-3123.

65 Kump, K., Whalen, C., Tishler, P.V., et al. (1994). Assessment of the validity and utility of a sleepsymptom questionnaire. American Journal of Respiratory and Critical Care Medicine, 150, 735-741.

64 Stacy, A.W., Newcomb, M.D., and Bentler, P.M. (1991). Personality, problem drinking, and drunk driving: Mediating, moderating, and direct-effect models. Journal of Personality and Social Psychology, 60, 795-811.

59 Ramaekers, J.G., Uiterwijk, M.M.C., and O’Hanlon J.F. (1992). Effects of Loratidine and Cetirizine on actual driving and psychometric test-performance, and EEG during driving. European Journal of Clinical Pharmacology, 42, 363-369.

Table 4

The most-cited publications: 1995-1999. (The numbers on the left indicate the number of the citations.)

58 Fitten, L.J., Perryman, K.M., Wilkinson, C.J., et al. (1995). Alzheimer and vascular dementias and driving - A prospective road and laboratory study. Journal of the American Medical Association, 273, $1360-1365$.

49 Hemmelgarn, B., Suissa, S., Huang, A., et al. (1997). Benzodiazepine use and the risk of motor vehicle crashes in the elderly. Journal of the American Medical Association, 278, 27-31.

43 Vainio, A., Ollilia, J., Matikainen, E., et al. (1995). Driving ability in cancer-patients receiving longterm morphine analgesia. Lancet, 346, 667-670.

40 O'Hanlon, J.F., and Ramaekers, J.G. (1995). Antihistamine effects on actual driving performance in a standard test: A summary of Dutch experience, 1989-94. Allergy, 50, 234-242.

39 Scott, E.S., Reppucci, N.D., and Woolard, J.L. (1995). Evaluating adolescent decision-making in legal contexts. Law and Human Behavior, 19, 221-244.

38 Redelmeier, D.A., and Tibshirani, R.J. (1997). Association between cellular-telephone calls and motor vehicle crashes. New England Journal of Medicine, 336, 453-458.

37 Findley, L., Unverzagt, M., Guchu, R., et al. (1995). Vigilance and automobile accidents in patients with sleep-apnea or narcolepsy. Chest, 108, 619-624.

37 Teran-Santos, J., Jimenez-Gomez, A., and Cordero-Guevara, J. (1999). The association between sleep apnea and the risk of traffic accidents. New England Journal of Medicine, 340, 847-851.

35 Cohn, L.D., MacFarlane, S., Yanez, C., et al. (1995). Risk-perception: Differences between adolescents and adults. Health Psychology, 14, 217-222.

35 Dinges, D.F. (1995). An overview of sleepiness and accidents. Journal of Sleep Research, 4 (Suppl. 2), 4-14.

35 Trobe, J.D., Waller, P.F., Cook Flannagan, C.A., et al. (1996). Crashes and violations among drivers with Alzheimer disease. Archives of Neurology, 53, 411-416. 
Tables 5 through 9 provide summary information about the most-cited publications. Table 5 groups the publications by the main topic(s), based on the title of the publication. Table 6 divides the publications by the type of the journal that they appeared in; analogous information by the country of origin of the lead author is in Table 7. There were six journals with more than one publication. These journals are listed in Table 8. Six organizations had more than one most-cited publication; they are listed in Table 9.

Table 5

Main topic(s) of the most-cited publications.

\begin{tabular}{|l|c|c|c|c|c|}
\hline \multirow{2}{*}{ Topic } & \multicolumn{5}{c|}{ Time period } \\
\cline { 2 - 6 } & $1980-1984$ & $1985-1989$ & $1990-1994$ & $1995-1999$ & Total \\
\hline \hline Drug side effects & 6 & & 2 & 3 & 11 \\
\hline Elderly drivers & & 3 & 4 & 3 & 10 \\
\hline Effects of disease & 2 & 1 & 1 & 3 & 7 \\
\hline Vision & 2 & 1 & 4 & & 7 \\
\hline Perception and cognition & 3 & & 1 & 2 & 6 \\
\hline Sleep disorders & & 1 & 2 & 3 & 6 \\
\hline Young drivers & & 1 & 1 & 2 & 4 \\
\hline Alcohol effects & & 2 & 1 & & 3 \\
\hline Risk taking & & 2 & 0 & 1 & 3 \\
\hline Self assessment & & 2 & & & 2 \\
\hline Driver distractions & & & & & 1 \\
\hline
\end{tabular}

Table 6

Types of journals with the most-cited publications.

\begin{tabular}{|l|c|c|c|c|c|}
\hline \multirow{2}{*}{ Journal type } & \multicolumn{5}{c|}{ Time period } \\
\cline { 2 - 6 } & $1980-1984$ & $1985-1989$ & $1990-1994$ & $1995-1999$ & Total \\
\hline \hline Medical & 9 & 4 & 6 & 9 & 28 \\
\hline Epidemiological & & 6 & 1 & & 7 \\
\hline Psychological & 1 & & 3 & 1 & 5 \\
\hline Law & & & & 1 & 1 \\
\hline
\end{tabular}


Table 7

Country of origin of the lead author in the most-cited publications.

\begin{tabular}{|l|c|c|c|c|c|}
\hline \multirow{2}{*}{ Country } & \multicolumn{5}{|c|}{ Time period } \\
\cline { 2 - 6 } & $1980-1984$ & $1985-1989$ & $1990-1994$ & $1995-1999$ & Total \\
\hline \hline United States & 4 & 6 & 8 & 6 & 24 \\
\hline United Kingdom & 5 & 1 & 1 & 1 & 8 \\
\hline The Netherlands & 1 & 1 & 1 & 1 & 4 \\
\hline Canada & & 1 & & 1 & 2 \\
\hline Finland & & 1 & & 1 & 1 \\
\hline New Zealand & & & & 1 & 1 \\
\hline Spain & & & & & \\
\hline
\end{tabular}

Table 8

Journals with more than one most-cited publication.

\begin{tabular}{|l|c|}
\hline \multicolumn{1}{|c|}{ Journal } & Frequency \\
\hline \hline Accident Analysis and Prevention & 4 \\
\hline Archives of Ophthalmology & 2 \\
\hline Archives of Physical Medicine and Rehabilitation & 2 \\
\hline British Medical Journal & 2 \\
\hline Journal of the American Medical Association & 2 \\
\hline New England Journal of Medicine & 2 \\
\hline
\end{tabular}

Table 9

Organizations with a lead author in more than one most-cited publication.

\begin{tabular}{|l|c|}
\hline \multicolumn{1}{|c|}{ Organization } & Frequency \\
\hline \hline University of Michigan, United States & 3 \\
\hline University of Virginia, United States & 2 \\
\hline University of Birmingham, United Kingdom & 2 \\
\hline University of California at Davis, United States & 2 \\
\hline University of California at Los Angeles, United States & 2 \\
\hline University of Leeds, United Kingdom & \\
\hline
\end{tabular}

